\title{
A TRAJETÓRIA DA EDUCAFRO NO ACESSO AO ENSINO SUPERIOR E SUA LUTA PELA IGUALDADE RACIAL ATRAVÉS DE CURSO PRÉ-VESTIBULAR POPULAR
}

\author{
William Alves Teixeira ${ }^{1}$
}

RESUMO: Em nosso texto trataremos da importância de uma instituição não governamental (Educafro) e sua relevância para uma parcela da sociedade civil. A fim de definir estes aspectos, abordaremos dados vividos e coletados em vários eventos e ações promovidos pela instituição em destaque, enfatizando o seu diferencial educacional e sua base na ação e na promoção da cidadania. Para os sociólogos Monica Pereira dos Santos e Marcos Moreira Paulino (2006), cidadania é caracterizada, fundamentalmente, como participação na democracia (com o poder nas mãos do povo e não nas mãos de uma minoria privilegiada): a partir deste enfoque, a Educafro abrange o tema de forma categórica, além de promover na pratica a atuação de todos os alunos perante as discussões atuais da política nacional. Com abrangência nacional, a Educafro (sediada em São Paulo) possui vários núcleos espalhados pela grande São Paulo e pelo estado de Minas Gerais (especialmente entre o Triangulo Mineiro e o Vale do Rio Doce).

Palavras-chave: Educação; Afrodescendentes; Sociedade Civil.

ABSTRACT: This paper deals with the importance of a Brazilian non-governamental nationwide institution called "Educafro". We enphasize its relevance to civil society in promoting citizenship. Citizenship, according to Monica Pereira dos Santos and Marcos Moreira Paulino (2006), is characterized by the participation in democracy: from this point of view, Educafro categorically approaches the topic, by promoting political discussions among its students for exemple.

Keywords: Education; African Descent; Civil Society.

\section{INTRODUÇÃO}

A Educafro tem um papel importante na inserção de jovens pobres e afrodescendentes no ensino superior. Como uma ONG ligada à Igreja Católica (proveniente da ordem franciscana no Brasil), a instituição coloca os jovens pobres e afrodescentes em evidência no cenário nacional, pautando temas que Santos e Paulino (2006) inserem no conjunto maior da cidadania. Trata-se, portanto, da formação de um cidadão critico e formador de opiniões, de modo que a cidadania, nesse sentido, é um conceito definido pelo gozo de todos os direitos civis e políticos de um Estado.

Hoje a Educafro tem como meta para seus alunos a cidadania como forma de promover a mudança social de classes. Para isso, todos os alunos contam

\footnotetext{
${ }^{1}$ Graduado em Pedagogia pela Faculdade Anhanguera de Sertãozinho. Graduando em Ciências Biológicas pela Faculdade São Luis de Jaboticabal e em Psicopedagogia pela Faculdade Anhanguera de Sertãozinho
} 
semanalmente com aulas de cidadania, palestras e provas teóricas e praticas sobre o assunto. A temática das cotas e do mérito no processo de inclusão na educação brasileira também tem sido muito discutida: a própria atuação de nossos alunos permite que eles percebam a importância da participação ativa nas esferas política e social.

Hoje existe uma discriminação racial mascarada que marginaliza os mais pobres (especialmente os afrodescendentes). Com base neste argumento, Magnoli (2009) destaca que, apesar de várias leis que garantem a igualdade de direitos a todos os seres humanos, ainda há casos de preconceito racial e social explícitos na sociedade contemporânea. Com esse enfoque, a instituição promove convênios com faculdades, além de lutar por cotas em universidades federais e estaduais defendendo o direito de acesso igualitário ao mercado de trabalho.

\section{OS OBJETIVOS DA EDUCAFRO PARA A SOCIEDADE BRASILEIRA}

A Educafro busca reunir pessoas solidárias com a causa social. Nesse sentido, a instituição desenvolve ações afirmativas para inclusão de pobres e negros nas universidades publicas federais e estaduais, bem como pleiteia bolsas de estudos em faculdades particulares - além de promover convênio com o governo de Cuba e da Venezuela na liberação de bolsas de estudos para alunos da periferia do Brasil. Esses convênios possuem um objetivo especifico, centrado, especialmente na formação de alunos pobres na área de Medicina e em cursos de alto prestígio na sociedade. Todo esse contexto descrito está baseado na criação de núcleos prévestibulares nas periferias das grandes cidades a fim de promover o surgimento de novos lideres e provocar nos professores o papel de cidadania. Todos os professores são voluntários nas suas funções acadêmicas, e isso é um diferencial, pois os professores promovem uma educação baseada em cidadania, de forma que a relação dos conteúdos com o cotidiano dos alunos é um método que coloca o aluno como protagonistas do conhecimento. O professor apresenta-se como mero mediador das aulas. Este enfoque está baseado em um dos grandes educadores internacionais: Boakari (1994), nesse sentido, coloca em pauta o grande papel dos professores na formação dos alunos, argumentando que o método tradicional cria um cidadão passivo e submisso: 
Acima de tudo, os professores que utilizam materiais didáticopedagógicos sem nenhuma preocupação com sua adaptabilidade humanística teriam uma parcela da contribuição na manutenção e transmissão de valores e crenças nacionais que compõem as forças socioculturais, que cotidianamente lutam contra a pessoa da criança negra, e contra o desenvolvimento de uma postura mais positiva em relação aos membros do seu grupo étnico-racial. (BOAKARI, 1994, p.23)

Com essa temática a Educafro luta pela mudança da educação de base e promove ações que ao longo do tempo farão a diferença na questão do mérito educacional. Porém, aos estudantes que infelizmente não podem voltar à educação de base, na Educafro tem um papel de luta por leis paliativas de ações afirmativas baseadas na inserção dos estudantes do ensino médio na educação superior.

A Educafro preocupa-se em formar pessoas, não apenas no sentido de sua inserção no ensino superior, mas de possibilitar que essas pessoas façam a diferença. Muitos de nossos alunos não possuem conhecimentos políticos, sociais e filosóficos, de modo que a convivência com professores, políticos, padres, freis e juristas permite que o aluno tenha uma visão multidisciplinar da educação e da sociedade. O papel do aluno passa de marginalizado para protagonista de sua historia: todo esse fundamento está baseado no ideário cristão franciscano, que orienta esta luta pela igualdade entre os povos em todas as esferas.

\section{A TRANSFORMAÇÃO DE UM SER HUMANO ATRAVÉS DA EDUCAFRO}

Como protagonista de uma historia similar a muitos alunos do ensino médio, gostaria de discutir minhas próprias vivências junto à Educafro. Com a idéia de que a escola mudaria a condição social e econômica, percebi que isso era uma utopia: notei que deveria ir além. A partir destas convicções, é possível afirmar que

Para estes brasileiros a escola é considerada o fator social determinante para corrigir as desigualdades sociais e colocar freios permanentes nos processos de proletarização da classe média e da miserabilidade dos pobres (BOAKARI, 1994, p. 21).

Em meados de 2003 e 2004, passei a atuar de uma forma ativa junto à Educafro na luta pela cidadania e pela igualdade de direitos. Em nossa empreitada, estivemos inúmeras vezes na Assembléia Legislativa do Estado de São Paulo, em 
manifestações na Avenida Paulista e em uma das lutas mais marcantes desta trajetória - viajamos a Brasília para lutar por um projeto de lei que hoje é um dos principais métodos de inserções de jovens brasileiros no Universo Acadêmico: o ProUni.

Este momento foi de extrema importância na minha formação como cidadão. Todos os participantes deste processo tiveram uma visão da sociedade civil, do cotidiano político e suas conjecturas, do excesso de policiais federais que agrediram de uma forma brutal estudantes, a luta pela igualdade de direitos e a retratação pública das autoridades em relação ao movimento, bem como o cumprimento de ações que fariam a diferença em um futuro próximo.

Dentro desta mesma perspectiva, conseguimos juntar varias pessoas que, carregando os mesmos ideais, atuaram ativamente nos embates e nas audiências publicas que se tornariam um fator determinante na nossa luta por uma educação igualitária. Nossos embates aconteciam com reitores e diretores de universidades de todos os níveis acadêmicos, porém nosso foco principal estava nas escolas de periferia a fim de que pudéssemos proclamar a nossa luta e argumentar que os próprios alunos eram a sociedade do futuro. Apesar das constantes retaliações de diretores e coordenadores, nunca desanimamos, pois a educação era nosso foco. De forma geral, todo o contexto vivido foi descrito por Santos e Paulino (2006).

\begin{abstract}
Crianças vindas de famílias pobres são, em geral, as que têm menos êxito, se avaliadas através de procedimentos convencionais de medida e as mais difíceis de serem ensinadas através de métodos tradicionais. As que tem menos poder na escola, são as menos capazes de fazer suas reivindicações ou de insistir para que suas necessidades sejam satisfeitas, mas são, por outro lado, as mais dependentes da escola para obter sua educação. (SANTOS E PAULINO, 2006, p. 71).
\end{abstract}

A nossa luta foi deflagrada com a criação do ProUni em 2005, quando uma grande parcela da juventude afrodescendente começou a pertencer ao mundo acadêmico. Nossa preocupação, neste novo cenário, era a discriminação dos alunos que entraram na faculdade através do "mérito". Com isso houve varias lutas até que, juntamente com o ProUni, foi editada uma lei que garante ao aluno o pleno direito de igualdade acadêmica. Para a Educafro, a inserção do estudante na universidade é apenas um dos tópicos importantes na formação de um cidadão: temos como foco a devolutiva deste aluno junto à sociedade, como demonstraremos neste gráfico: 
Aluno de escola publica sem perspectiva de um Ensino Superior.

Conhece o Curso da Educafro através de profissionais que foram alunos da mesma.
Aluno da Educafro com noções de cidadania. A formação de um Cidadão critico e formador de opinião.

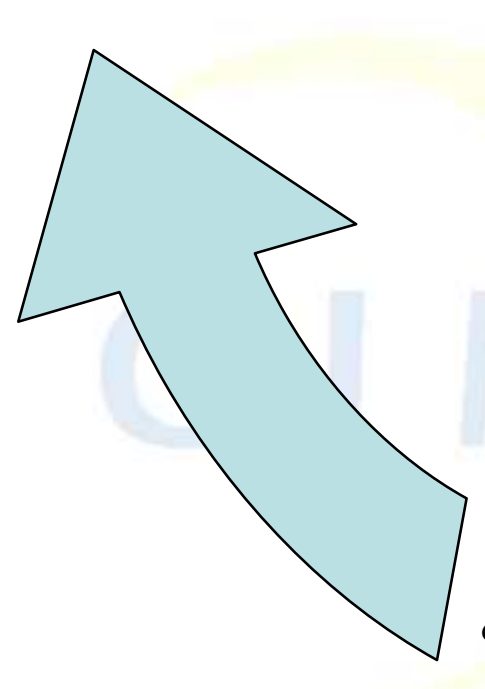

Universitário com formação critica e que ao se formar tem o dever de transmitir sua

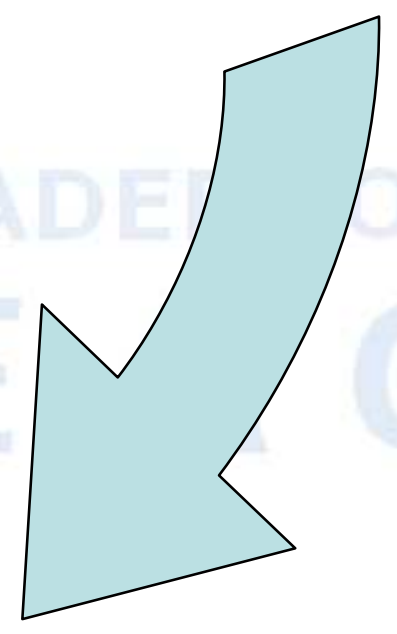
trajetória de luta e de conquistas aos alunos do ensino médio, para que os mesmo percebam que possuem as mesmas chances.

Este esquema representa o principal foco da Educafro em relação a seus alunos. Há, inclusive, vários alunos da Educafro atuando em vários seguimentos da sociedade: podemos destacar, por exemplo, Patrícia Iria Maximiano, negra, filha de mãe solteira que não tinha perspectiva de um futuro promissor, mas graças à Educafro, em 2007, ela concluiu o curso de Fisioterapia na Faculdade São Francisco de Bragança Paulista, de modo que hoje atua na área da saúde e promove ajuda a pessoas carentes na sua comunidade. Há vários alunos que estudaram Medicina em 
Cuba e, com seu diploma e CRM em mãos, atuaram nas comunidades mais carentes do Nordeste do Brasil. Para a Educafro, isso é fazer a diferença: essas pessoas são exemplos de que as aulas de cidadania surtiram efeito na formação acadêmica. Os profissionais poderiam ser apenas médicos ou fisioterapeutas bem sucedidos nos grandes centros, perdendo toda ligação com o passado.

\section{A DISCRIMINAÇÃO RACIAL, EDUCACIONAL E DE MÉRITO}

Colocando o prognóstico da formação da sociedade brasileira, a Educafro define em trajetória pontos importantes da formação humana. Pela luz da antropologia, da filosofia e da sociologia, a discriminação racial, educacional e de mérito estão intimamente interligadas. Para a Antropologia, Abbagnano (2000) nos define que racismo é a doutrina na qual se manifesta os valores de uma raça em detrimento de outra. O Brasil, país que recebeu pessoas de várias partes do mundo, apresenta uma forte miscigenação de raça, construindo em seu contexto social uma falsa igualdade racial. No contexto da imigração de vários grupos étnicos, no entanto, houve uma parcela da sociedade que não veio por livre e espontânea vontade: trata-se dos negros escravizados, jogados em porões de navios negreiros, obrigados a trabalhar de forma desumana. Com esse histórico, o Brasil foi o último país a abolir a escravidão: após pouco mais de cem anos da Abolição da escravatura, temos resquícios do descaso do Estado com essa parcela da sociedade. A Igreja, por sua vez, participou deste processo de escravidão - no entanto, através da Educafro, a própria Igreja busca uma forma de "retratação". Os conceitos sociológicos de que negros, mulheres e pobres são incapazes de realizar atividades superiores vem desde o século XIX:

[...] (pobres eram pobres porque faltavam sentimentos, virtudes e valores nobres); do mesmo modo as mulheres teriam posição subordinadas devido a características de seu sexo e os negros eram escravizados ou mantidos em situação de "ralé" seria intelectual e moralmente e incapacitada para a civilização (GUIMARÃES, 2005, p. 32).

O homem delimita uma ideologia para uma parcela da sociedade, e quem difere desta é inferior e incapaz de qualquer superação moral ou ética. Para muitos filósofos, o conhecimento é a vertente que põe o negro, a mulher e o pobre na 
escala de seres humanos respeitados perante a sociedade. A luta pela igualdade de valores de uma sociedade, passa pela família, escola e sociedade - temos o dever de propagar essa vertente. A partir deste ponto, com novas idéias e ideais convictos teremos uma sociedade mais justa.

\section{CONSIDERAÇÕES FINAIS}

Este pequeno texto discutiu algumas facetas de uma sociedade desigual, enfatizando as maneiras encontradas por vários indivíduos para transformar este cenário. Neste contexto, apresentamos a Educafro, bem como a sua importância para os estudantes de baixa renda e o seu diferencial para a sociedade. Tentamos ainda provocar uma releitura do nosso passado, discutindo os contextos sociológico, antropológico e filosófico da discriminação racial, educacional e de mérito. De certa forma, afirmamos que estes conceitos criaram a luta da Educafro. No Brasil, país de discriminação racial mascarada, todos os dias há pessoas sofrendo verbalmente e fisicamente ações do preconceito racial e educacional.

A luta por uma educação de qualidade e de garantia de acesso a todos trouxe nessa última década muitos benefícios para os alunos da Educafro. Vários programas foram criados, entre eles destacamos o SISU (Sistema de Seleção Unificada) e o ProUni (Programa Universidade Para Todos), além de várias parcerias construídas pela Educafro com instituições privadas: FGV (Fundação Getulio Vargas - RJ e SP), PUC-RIO (Pontifícia Universidade Católica do Rio de Janeiro), USF (Universidade São Francisco) entre outras.

O destaque adquirido pela Educafro no cenário nacional oferece à instituição a oportunidade de atingir todas as esferas do conhecimento. É muito fácil fazer um curso pré-vestibular popular funcionar: porém, o grande diferencial está na forma como vamos trabalhar com esses alunos, bem como na política que adotaremos para que o aluno não seja apenas "mais um" no mercado de trabalho - tornando-se, antes, um cidadão e um profissional competente naquilo que faz. Enfim, a partir de minha própria trajetória, construí um diferencial na minha turma do Ensino Médio: em sua maioria proletários de mão de obra barata, muitos dos colegas perderam na vida o seu propósito. A Educafro, no entanto, me ofereceu uma perspectiva diferente 
e academicamente superior às demais. O que forma o cidadão não é a sua singularidade, mais sim a sua pluralidade no repasse do conhecimento acadêmico.

\section{REFERÊNCIAS BIBLIOGRAFICAS}

ABBAGNANO, Nicola. Dicionário de Filosofia. 4. Ed. São Paulo: Martins Fontes, 2000.

BOAKARI, Francis Musa. As crianças e a socialização que produz o fracasso escolar. In: VEIGA NETO, Alfredo (org.). Sociologia da Educação: publicação do GT-ANPED. Porto Alegre: ANPED, 1994. p. 21-42.

GUIMARÃES, Antonio Sergio Alfredo. Definindo Racismo. In: GUIMARÃES, Antonio Sérgio Alfredo. Racismo e anti-racismo no Brasil. 2. ed. São Paulo: Editora 34, 2005.

MAGNOLI. Demetrio. Uma gota de sangue: história do pensamento racial. São Paulo: Contexto, 2009.

PAULINO, Marcos Moreira; SANTOS, Monica Pereira dos Santos (orgs.). Inclusão em Educação: culturas, políticas e praticas. São Paulo: Cortez, 2006. 